\title{
The opioid crisis and nudge theory
}

Yanbo Guo'; Jehonathan Pinthus ${ }^{1}$; Benjamin Davies ${ }^{2}$

${ }^{1}$ Division of Urology, McMaster University, Hamilton, ON, Canada; ${ }^{2}$ Department of Urology

University of Pittsburgh, Pittsburgh, PA, United States

Cite as: Can Urol Assoc J 2019 November 5; Epub ahead of print. http://dx.doi.org/10.5489/cuaj.6054

Published online November 5, 2019

$* * *$

How do we change? That's the question filled the room after our thought-provoking McMaster Department of Surgery Chair Rounds by the Drs. Dorothy Bakker, Benjamin Davies, and Jason Busse. Dr. Bakker is a formidable advocate in the opioid crisis and many of us are familiar with the tragic story of her 25-year-old son passing away from an opioid overdose. She was a powerful and personal introduction to our discussion of the opioid epidemic.

The evidence regarding opioid related deaths are staggering. American data shows a 1700\% exponential increase in the number of opioid deaths over the last 30 years. ${ }^{1}$ In Canada, there have been roughly 10,000 opioid deaths since $2016 .{ }^{2}$ It is not a coincidence that countries with the most available opioid prescriptions are also those with the most opioid deaths, and that the rise in the number of prescriptions are paralleled by the rise in deaths. North America has some of the highest number of opioid prescriptions per capita. There are 13 American states with more opioid prescriptions than people. ${ }^{3}$ In Canada, there are 6 opioid prescriptions for every 10 people. ${ }^{2}$

Surgeons bear some of the responsibility for this over availability of opioids. While the total number of new opioid prescriptions decreased from 2010 to 2016, surgeons actually prescribed $17.6 \%$ more. ${ }^{4}$ Reasons for this are multifactorial. They include patient pressure, the influence of pharmaceutical companies, and an emphasis on pain management as an outcome. While pain control and patient comfort remains a priority, there is evidence that the majority of these prescriptions are not actually helping. Hill et al found that $72 \%$ of the opioids prescribed for general surgery outpatient procedures go unused..$^{5}$ In urology, there is similar data showing that $67 \%$ of these prescriptions go unused. ${ }^{6}$

Ultimately, this contributes to the growing evidence that physicians, particularly surgeons, are overprescribing opioids that do not necessarily reduce patient pain but that do cause real harm by contributing to the opioid crisis.

For most physicians, this really isn't anything controversial. However, despite recognizing the problem, it has proven to be extremely difficult to change physician behavior. Traditional 
methods for inciting change include guidelines, continuing medical education, and modifying incentives, but these can be resource-intensive and of limited effectiveness.

Nudge theory is a concept in behavioural science that proposes positive reinforcement and indirect suggestions as way to influence behavior. These are simple, low cost interventions that alter behavior in predictable ways. One of its major proponents, Richard Thaler was awarded the 2017 Nobel Prize in Economics Sciences for his work in nudge theory and for bringing it to mainstream attention. His favorite example of a nudge is a small picture of a fly in a urinal, located near the drain. This had the effect of giving men something to aim for when voiding. When Amsterdam's Schiphol Airport applied this idea, they estimated an 80\% reduction in urine spillage and an $8 \%$ reduction in total bathroom cleaning costs.

In the UK, the Behaviour Insights Team, also known as the "Nudge Unit", was an organization created to improve government services and compliance using nudge theory. They had numerous successful projects in the UK and have consulted for numerous other governments around the world. An example of their successes was a program to increase the number of fines being paid to the UK Court Services. By simply sending a text message reminder along with the standard letters, they doubled the value of the fines being paid on time and decreased collection costs by $\$ 30$ million. ${ }^{8}$ They also demonstrated that physicians are susceptible to nudge theory. To encourage UK doctors to pay outstanding tax liabilities, reminder letters were sent. The first group received a generic letter; the second group received a letter that emphasized that this was a campaigned focused on doctors, and the third group received a similarly targeted letter but also with an additional moral message about how much trust the public has in doctors. The third group had a response rate ten times that of the generic letter. ${ }^{8}$

The University of Pittsburgh Department of Urology is a pioneer in the use of nudge theory to reduce opioid over prescription. In addition to traditional methods, such as lectures and guidelines, "nudges" have also been implemented. "Nudges" include weekly personalized text reminders to prescribers and department-wide emails detailing the number of prescriptions from each provider. Preliminary data has been extremely promising, reducing the number of opioids prescribed after prostatectomies and nephrectomies by more than half. They also showed that there was no significant difference in patient-reported outcomes such as pain, ambulation, and mood.

The opioid crisis is an epidemic that is isn't going away and the role of opioid over prescription has to be recognized. Changing prescriber behaviour is a challenge, for which nudge theory may be an effective and efficient solution. How do we change? Maybe with just a nudge. 


\section{References}

1. Jalal H, Buchanich JM, Roberts MS, et al. Changing dynamics of the drug overdose epidemic in the United States from 1979 through 2016. Science 2018;361

2. Special Advisory Committee on the Epidemic of Opioid Overdoses. National report: Apparent opioid-related deaths in Canada (January 2016 to September 2018). Public Health Agency of Canada 2019

3. IMS Institute for Healthcare Informatics. HSRN data brief: national prescription audit 2016.

4. Larach DB, Waljee JF, Hu HM, et al Patterns of Initial Opioid Prescribing to OpioidNaive Patients. Annals of Surgery 2018;1.

5. Hill MV, McMahon ML, Stucke RS, et al. Wide Variation and Excessive Dosage of Opioid Prescriptions for Common General Surgical Procedures. Annals of Surgery 2017; 265;709-14.

6. Bates C, Laciak R, Southwick A, et al. Overprescription of Postoperative Narcotics: A Look at Postoperative Pain Medication Delivery, Consumption and Disposal in Urological Practice. Journal of Urology 201 1;185;551-55.

7. Thaler RH, and Cass RS. Nudge: Improving Decisions Using the Architecture of Choice. Yale University Press 2008.

8. Halpern D, and Owain S. Inside the Nudge Unit: How Small Changes Can Make a Big Difference. WH Allen 2016.

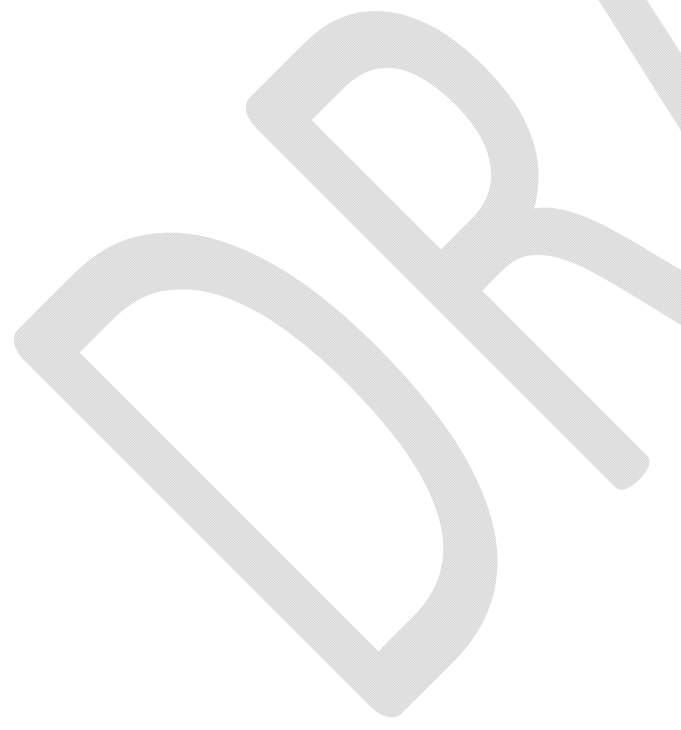

